\title{
Effects of Terminal Mesogens on Thermal Properties of Dimeric, Trimeric, and Tetrameric Model Compounds for Main Chain Liquid Crystalline Polymers
}

\author{
Yoshihiro Ogawa \\ Department of Chemistry, Faculty of General Education, Kumamoto University, \\ Kumamoto 860, Japan
}

(Received May 8, 1995)

\begin{abstract}
Three series of oligomers as models of main chain liquid crystalline polyesters were synthesized from 4,4'biphenol as internal mesogens, suberic acid as spacers, and para-substituted phenols as different terminal mesogens at both ends of the molecule. The oligomers were separated by a silica gel column and pure dimeric, trimeric, and tetrameric model compounds were obtained. The effects of the degree of polymerization and terminal mesogens on thermal properties of these model compounds were studied. No dimers showed a liquid crystalline phase. Trimers which had the terminal group $\mathrm{CH}_{3} \mathrm{O}$ or $\mathrm{Ph}$ were monotropic nematic, while the trimer which had the terminal group $\mathrm{CN}$ was enantiotropic nematic. Tetramers were enantiotropic nematic. Increasing the degree of polymerization generated the nematic phase and increased the regularity of nematic phase. The regularity of the nematic phase of trimers and tetramers is remarkably larger than that of low molecular liquid crystals. Terminal mesogens have effect on transition temperatures, but have almost no effect on entropies of nematic-isotropic transition. There existed Gray's order, $\mathrm{Ph}>\mathrm{CN}>\mathrm{CH}_{3} \mathrm{O}$ between nematic-isotropic transition temperatures and terminal mesogens of tetramers.
\end{abstract}

KEY WORDS Liquid Crystalline Polymer / Model Compound / Tetrameric Liquid Crystal / Terminal Mesogen / Degree of Polymerization / Nematic Phase /

As model compounds of semiflexible main chain liquid crystalline polymers, dimers with mesogen groups at both ends of spacer are generally used. These dimers show very similar thermal properties to liquid crystalline polymers. ${ }^{1-3}$ For example, for dimers and polymers, parity effect of spacer length is more distinctive than low molecular liquid crystals. Here, parity effect means that transition temperature, degree of orientational order and transition entropy from nematic phase to isotropic liquid increase and decrease alternately in a zigzag fashion when the number of methylene units in the spacer is varied. The other similarity is that regularity of nematic phase of dimers and polymers with an even number of methylene units is considerably larger than that of low molecular liquid crystals with the same units. $^{3}$

So far, study of model compounds has been carried on the relation of structural elements and liquid crystalline properties. But if we want to understand the distinction between low molecular liquid crystals and liquid crystalline polymers, it is more necessary to make clear how much the degree of polymerization and kinds of terminal mesogens effect the generation of liquid crystals and stability. There are some reports on relation between the degree of polymerization and liquid crystalline properties, for example, studies about trimeric, ${ }^{4}$ tetrameric, ${ }^{5,6}$ and pentameric ${ }^{7}$ model compounds but no report on the kinds of terminal mesogens and liquid crystalline properties for trimeric and tetrameric model compounds.

In this study, as a model of a liquid crystalline polyester consisted of 4,4'-biphenol and suberic acid, we took dimeric (2-X), trimeric (3-X), and tetrameric (4-X) model compounds with different terminal mesogens $\left(\mathrm{X}=\mathrm{CH}_{3} \mathrm{O}, \mathrm{CN}\right.$, and $\left.\mathrm{Ph}\right)$ as shown below, and investigated how terminal mesogen and internal mesogen affect generation of liquid crystals.

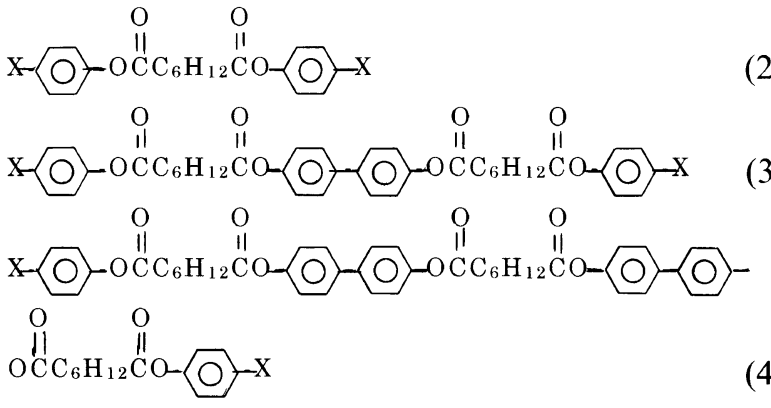

\section{EXPERIMENTAL}

\section{Materials}

Suberic acid dichloride was obtained by refluxing suberic acid and thionyl chloride. After 12 hours refluxing of 4,4'-biphenol and suberic acid dichloride (mol ratio $3: 10$ ) in dichloroethane, excess para-substituted phenols were added, and continued for 12 hours refluxing. We obtained a multimeric mixture. This mixture was separated by the silica gel column. Toluene, benzene, and dichloroethane were used as eluents. The results of elemental analysis of dimers, trimers, and tetramers are tabulated in Table I. Elemental analysis results were in good agreement with calculated values. The structures of the compounds were also confirmed by IR and proton NMR spectra.

\section{Measurements}

DSC measurements were performed with a Rigaku DSC 8230-TAS 100 system, at a heating rate of $3 \mathrm{Km}^{-1}$. Heat quantity was determined from peak area of DSC based on Indium as standard. Identification of the liquid crystal phase was carried out by an Olympus BH-2 polarization microscope, attached to the heating apparatus, Mettler FP 80/82. 


\section{RESULTS AND DISCUSSION}

\section{Effects of Terminal Mesogens}

Table II shows thermodynamic data for each dimer, trimer, and tetramer. No dimers showed the liquid crystalline phase. DSC of dimers, 2- $\mathrm{CH}_{3} \mathrm{O}, 2-\mathrm{CN}$, and 2-Ph, showed single peaks, and heats of fusion were

Table I. Elemental analysis of dimers, trimers, and tetramers

\begin{tabular}{lccc}
\hline \multicolumn{1}{c}{$n-\mathrm{X}$} & $\mathrm{C} \%$ & $\mathrm{H} \%$ & $\mathrm{~N} \%$ \\
\hline $2-\mathrm{CH}_{3} \mathrm{O}$ & $68.5(68.4)^{\mathrm{a}}$ & $6.85(6.84)$ & \\
$2-\mathrm{CN}$ & $70.4(70.2)$ & $5.44(5.36)$ & $7.44(7.44)$ \\
$2-\mathrm{Ph}$ & $80.3(80.3)$ & $6.33(6.32)$ & \\
\hdashline $3-\mathrm{CH}_{3} \mathrm{O}$ & $71.0(71.0)$ & $6.57(6.52)$ & \\
$3-\mathrm{CN}$ & $71.9(72.0)$ & $5.71(5.75)$ & $4.25(4.00)$ \\
$3-\mathrm{Ph}$ & $78.0(77.8)$ & $6.26(6.28)$ & \\
\hline $4-\mathrm{CH}_{3} \mathrm{O}$ & $71.8(71.9)$ & $6.38(6.43)$ & \\
$4-\mathrm{CN}$ & $72.4(72.4)$ & $6.18(6.11)$ & $2.73(3.06)$ \\
$4-\mathrm{Ph}$ & $76.8(76.7)$ & $6.31(6.26)$ & \\
\hline
\end{tabular}

${ }^{a}$ Values in parentheses are those calculated. almost the same independent of terminal groups. Figure 1 shows DSC melting curves of trimers, $3-\mathrm{CH}_{3} \mathrm{O}$ (a), 3-CN (b), and 3-Ph (c). Only 3-CN showed two endothermic peaks on heating. Between two peaks we observed a schlieren structure, which is characteristics of the nematic phase. The first peak corresponds to the transition from crystal to nematic phase and second peak, from nematic to isotropic phase. Other trimers such as $3-\mathrm{CH}_{3} \mathrm{O}$ and $3-\mathrm{Ph}$ did not show the liquid crystalline phase on heating, but the nematic phase on cooling, as shown in Figure 2. That is to say, $3-\mathrm{CN}$ is enantiotropic and others are monotropic.

For liquid crystalline polymers, $\Delta S_{\mathrm{NI}} / \Delta S_{\mathrm{KI}}$ is often used as a measure to represent the degree of order in the nematic phase relative to that of the crystal phase. Here, $\Delta S_{\mathrm{NI}}$ is the entropy of nematic-isotropic (N-I) phase transition and $\Delta S_{\mathrm{KI}}$ is the entropy of crystal-isotropic (K-I) phase transition. When a liquid crystal is monotropic, $\Delta S_{\mathrm{IN}} / \Delta S_{\mathrm{KI}}$ is used. Here, $\Delta S_{\mathrm{IN}}$ is the entropy of isotropic-nematic (I-N) phase transition. These values for trimers were $0.11-0.14$, as shown in Table II, similar to those of polymers $0.1-0.3,{ }^{8}$ and are considerably

Table II. Thermodynamic properties of dimers, trimers, and tetramers

\begin{tabular}{|c|c|c|c|c|c|c|}
\hline \multirow{2}{*}{$n-\mathrm{X}$} & Transition temperature ${ }^{\mathrm{a}}$ & $\Delta H_{\mathrm{KI}}$ & $\Delta S_{\mathrm{KI}}$ & $\Delta S_{\mathrm{IN}}$ & $\Delta S_{\mathrm{NI}}$ & \multirow{2}{*}{$\Delta S_{\mathrm{NI}}\left(\Delta S_{\mathrm{IN}}\right) / \Delta S_{\mathrm{KI}}$} \\
\hline & ${ }^{\circ} \mathrm{C}$ & $\mathrm{kJ} \mathrm{mol}^{-1}$ & $\mathrm{JK}^{-1} \mathrm{~mol}^{-1}$ & $\mathrm{JK}^{-1} \mathrm{~mol}^{-1}$ & $\mathrm{JK}^{-1} \mathrm{~mol}^{-1}$ & \\
\hline $2-\mathrm{CH}_{3} \mathrm{O}$ & K $121 \mathrm{I}$ & 63.1 & 160 & & & \\
\hline $2-\mathrm{CN}$ & K $125 \mathrm{I}$ & 63.7 & 161 & & & \\
\hline 2-Ph & K 148 I & 63.7 & 152 & & & \\
\hline $3-\mathrm{CH}_{3} \mathrm{O}$ & K $154 \mathrm{I}(\mathrm{I} 143 \mathrm{~N} 137 \mathrm{~K})^{\mathrm{b}}$ & 91.1 & 213 & 23.2 & & 0.109 \\
\hline $3-\mathrm{CN}$ & K 142 N 152 I & 72.6 & 174 & & 23.6 & 0.136 \\
\hline $3-\mathrm{Ph}$ & K 184 I(I 177 N 170 K) & 89.5 & 197 & 26.3 & & 0.134 \\
\hline $4-\mathrm{CH}_{3} \mathrm{O}$ & K 186 N 196 I & 120 & 252 & & 31.4 & 0.125 \\
\hline $4-\mathrm{CN}$ & K 171 N 206 I & 96.5 & 214 & & 34.8 & 0.163 \\
\hline 4-Ph & K 205 N 218 I & 115 & 240 & & 34.5 & 0.144 \\
\hline
\end{tabular}

${ }^{\mathrm{a}}$ Values refer to transition temperature between two phases by DSC measurements. $\mathrm{K}=$ crystalline, $\mathrm{N}=$ nematic, $\mathrm{I}=$ isotropic. ${ }^{\mathrm{b}}$ Monotropic transitions in parentheses.

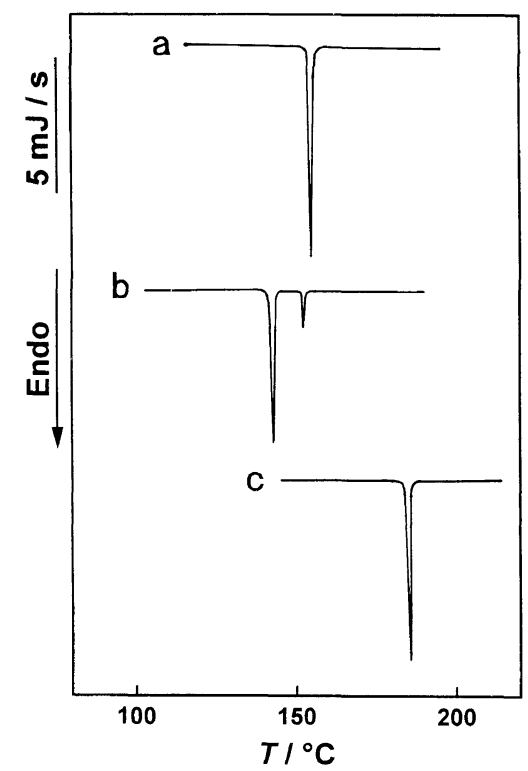

Figure 1. DSC heating curves of trimers: (a) $3-\mathrm{CH}_{3} \mathrm{O}$; (b) $3-\mathrm{CN}$; (c) $3-\mathrm{Ph}$

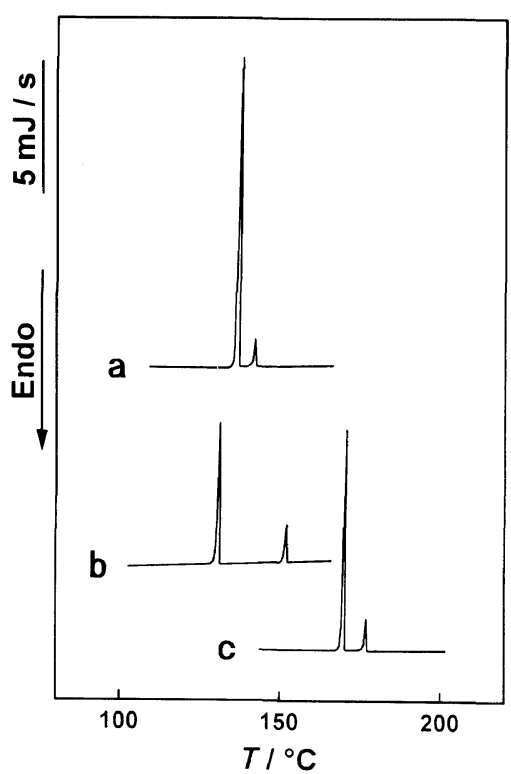

Figure 2. DSC cooling curves of trimers: (a) $3-\mathrm{CH}_{3} \mathrm{O}$; (b) $3-\mathrm{CN}$; (c) 3-Ph. 


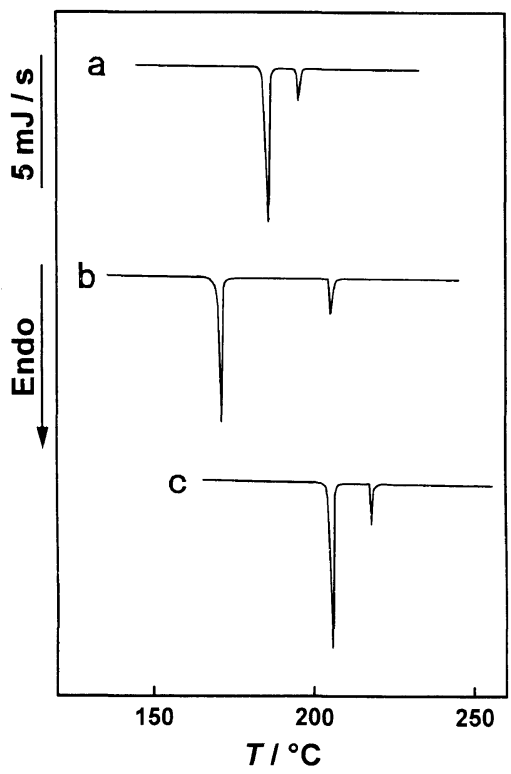

Figure 3. DSC heating curves of tetramers: (a) $4-\mathrm{CH}_{3} \mathrm{O}$; (b) $4-\mathrm{CN}$; (c) 4-Ph.

larger than those of RF-type (rigid-flexible sequence) and FRF-type (flexible-rigid-flexible) low molecular liquid crystals which are $0.03-0.05$. Therefore the nematic regularity of trimers is remarkably larger than that of low molecular liquid crystals. Terminal mesogens have little effect on the regularity of the nematic phase because $\Delta S_{\mathrm{NI}}\left(\Delta S_{\mathrm{IN}}\right) / \Delta S_{\mathrm{KI}}$ are almost the same independent of the terminal mesogen.

Figure 3 shows DSC melting curves of tetramers. Tetramers, 4- $\mathrm{CH}_{3} \mathrm{O}, 4-\mathrm{CN}$, and 4-Ph show two endothermic peaks. The first peak at low temperature corresponded to crystal-nematic transition and the second peak at high temperature to nematic-isotropic transition. Nematic -isotropic transition temperature $\left(T_{\mathrm{NI}}\right)$ of tetramers increased in a uniform manner for the series of substituents, and the ability of substituents to stabilize the mesophase followed the following order, $\mathrm{Ph}>\mathrm{CN}>$ $\mathrm{CH}_{3} \mathrm{O}$, shown in Table II. This order coincides with the results for low molecular liquid crystals stated by Gray. ${ }^{9}$ Gray explained substituent effects on the stability of nematic phase on the basis of enhanced polarizability or polarity of mesogenic units. This order was also reported for dimeric model compounds. ${ }^{10}$ It is very interesting in a point such as that Gray's order existed on the value of $T_{\mathrm{NI}}$ of tetramers, in spite of two much longer and stronger internal mesogens, 4,4'-biphenol, than two terminal mesogens, in the molecules of tetramers. Temperatures over which the nematic phase existed were 10 , 35 , and $13{ }^{\circ} \mathrm{C}$ for $4-\mathrm{CH}_{3} \mathrm{O}, 4-\mathrm{CN}$, and 4-Ph, respectively and the order of the temperature range, $\mathrm{CN}>\mathrm{Ph}>$ $\mathrm{CH}_{3} \mathrm{O}$, is different from that of dimers or monomers. It seems that the discrepancy of the order is due to differences among crystal structures of tetramers. $\Delta S_{\mathrm{NI}} /$ $\Delta S_{\mathrm{KI}}$ of tetramers are $0.13-0.16$. The regularity of nematic phase of tetramers is much larger than that of low molecule liquid crystals, and the effects of terminal groups for nematic regularity are small.

\section{Effects of the Degree of Polymerization}

For multimerics having the same terminal mesogens, we studied the effects of the degree of polymerization. Though dimers 2- $\mathrm{CH}_{3} \mathrm{O}$ and $2-\mathrm{Ph}$ did not show the liquid crystal phase, trimers $3-\mathrm{CH}_{3} \mathrm{O}$ and $3-\mathrm{Ph}$ showed the monotropic nematic phase. Tetramers $4-\mathrm{CH}_{3} \mathrm{O}$ and 4-Ph showed the enantiotropic nematic phase. Thus, increasing the degree of polymerization generates the nematic phase, and transformation of a monotropic liquid crystalline compound to an enantiotropic one.

Dimer 2-CN did not show the liquid crystal phase, but trimer 3-CN and tetramer 4-CN showed the enantiotropic nematic phase. The temperature, over which the nematic phase existed, was $10^{\circ} \mathrm{C}$ for the trimer $3-\mathrm{CN}$ and $35^{\circ} \mathrm{C}$ for the tetramer $4-\mathrm{CN}$. Increasing the degree of polymerization led to a greater temperature range of the nematic phase.

$\Delta S_{\mathrm{NI}}\left(\Delta S_{\mathrm{IN}}\right) / \Delta S_{\mathrm{KI}}$ for trimers $3-\mathrm{CH}_{3} \mathrm{O}, 3-\mathrm{CN}$, and $3-\mathrm{Ph}$ were $0.109,0.136$, and 0.134 , respectively and $\Delta S_{\mathrm{NI}} / \Delta S_{\mathrm{KI}}$ for tetramers as $4-\mathrm{CH}_{3} \mathrm{O}, 4-\mathrm{CN}$, and 4- $\mathrm{Ph}, 0.125,0.163$, and 0.144 , respectively, shown in Table II. $\Delta S_{\mathrm{NI}} / \Delta S_{\mathrm{KI}}$ increase about $10 \%$. That is, the regularity of nematic phase depends on the degree of polymerization.

It is speculated that the effects of the degree of polymerization described above results from increase of the ratio of longer and stronger internal mesogens, 4,4'biphenyl ester, to terminal mesogens, 4-methoxyphenyl, 4-cyanophenyl, and 4-phenylphenyl esters.

\section{Entropy Changes for the Crystal-Isotropic and Nematic- Isotropic Phase Transitions}

To study the thermodynamic behavior of liquid crystalline polymer, the entropy per mol of repeat unit (mru) from crystal to isotropic phase transition, $\Delta s_{\mathrm{KI}}$, is very important. However, it is impossible to get $\Delta s_{\mathrm{KI}}$ of liquid crystalline polymers because of low crystallinity. Many flexible spacers seem to be poorly ordered in the crystal. $^{11} \mathrm{We}$ define trimers and tetramers as $\mathrm{A}-\mathrm{B}-\mathrm{A}$ and $\mathrm{A}-\mathrm{B}-\mathrm{B}-\mathrm{A}$, respectively, where $\mathrm{A}$ and $\mathrm{B}$ represent terminal mesogenic groups and the repeating unit, respectively, as shown below.

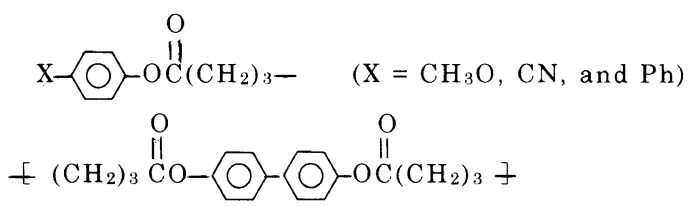

If we subtract $\Delta S_{\mathrm{KI}}$ of trimers from $\Delta S_{\mathrm{KI}}$ of tetramers, we obtain precisely $\Delta s_{\mathrm{KI}}$ of repeating unit B. By actual calculation using the data of Table II, the calculated value of $\Delta s_{\mathrm{KI}}$ for $\mathrm{CH}_{3} \mathrm{O}, \mathrm{CN}$, and $\mathrm{Ph}$ series were 39,40 , and $43 \mathrm{~J} \mathrm{mru}^{-1} \mathrm{~K}^{-1}$, respectively. Average $\Delta s_{\mathrm{KI}}$ becomes $41 \mathrm{~J} \mathrm{mru}^{-1} \mathrm{~K}^{-1}$. This is a little smaller than that of polymer PB6, which has same repeating unit, $61 \mathrm{~J}$ $\mathrm{mru}^{-1} \mathrm{~K}^{-1} .{ }^{12}$ In the same way, if we subtract $\Delta S_{\mathrm{NI}}$ of trimers from $\Delta S_{\mathrm{NI}}$ of tetramers, we obtain precisely $\Delta s_{\mathrm{NI}}$. The calculated $\Delta s_{\mathrm{NI}}$ for a nematic compound having terminal group $\mathrm{CN}$ is $11.2 \mathrm{~J} \mathrm{mru}^{-1} \mathrm{~K}^{-1}$. Because polymer PB6 shows no nematic and smectic, so $\Delta s_{\mathrm{NI}}$ of the compound and polymer PB6 are not comparable.

\section{REFERENCES}

1. A. Blumstein, M. Poliks, and E. Stickle, Mol. Cryst. Liq. Cryst., 129, 375 (1985). 
2. A. Jin, E. J. Choi, S. C. Ryu, and R. W. Lenz, Polym. J., 18, 63 (1986).

3. A. Abe, H. Furuya, R. N. Shimizu, and S. Y. Nam, Macromolecules, 28, 96 (1995).

4. H. Furuya, K. Asahi, and A. Abe, Polym. J., 18, 779 (1986).

5. A. Griffin, S. Sullivan, and W. Hughes, Liquid Crystals, 4, 677 (1989).

6. Y. Ogawa and K. Takamizawa, Polym. J., 21, 551 (1989)

7. A. Faradet and W. Heitz, Makromol. Chem., 188, 1233 (1987).
8. A. Krigbaum and F. Salaris, J. Polym. Sci., Polym. Phys. Ed., 16, 883 (1978).

9. G. W. Gray, Mol. Cryst. Liq. Cryst., 7, 127 (1969).

10. A. Jin, Y-S. Chung, J-S. Kang, and R. W. Lenz, Mol. Cryst. Liq. Cryst. (Letters), 82, 261 (1982).

11. A. Grebowicz and B. Wunderlich, J. Polym. Sci., Polym. Phys. Ed., 21, 141 (1983).

12. A. Krigbaum, J. Watanabe, and T. Ishikawa, Macromolecules, 16, 1271 (1983). 